$0.4^{2} \mathrm{~g}$ of $\mathrm{NaH}_{2} \mathrm{PO}_{4} \cdot \mathrm{H}_{2} \mathrm{O}$ are replaced by $2.86 \mathrm{~g}$ of $\mathrm{K}_{2} \mathrm{HPO}_{4}$ and $0.49 \mathrm{~g}$ of $\mathrm{KH}_{2} \mathrm{PO}_{4}$. Somewhat less color is obtained with the potassium salts. However, this inhibition is of the color development and not the enzyme activity.

Another difficulty with the procedure is the marked instability of oxalacetic acid which serves as the standard. The use of an enzyme standard would obviate this difficulty. Recently a commercial serum enzyme standard (Versatol ${ }^{\mathbb{B}}$-E, General Diagnostics Div., Morris Plains, N.J.) has become available in which glutamic-oxalacetic transaminase is standardized at over 300 units/1. To use this preparation as a standard, accurate dilutions in $0.85 \% \mathrm{NaCl}$ representing $100,75,50,25, \mathrm{I2.5}$ and $0 \%$ of the undiluted standard are assayed following the procedure given for serum. The standard curve is obtained by plotting optical density against transaminase units which are calculated from the dilution factors.

Our data with the Reitman-Frankel procedure were obtained by attempting to interpret the calibration charts in their paper which were reduced to a size inadequate for precise interpolation. Further work with the Reitman-Frankel method, using calibration tables supplied by the authors (personal communication), has shown much better correlation with the Karmen ultraviolet assay than we indicated in our paper.

Department of Biochemistry,

ARthur L. Babson

The Warner-Lambert Research Institute, PaUl O. Shapiro Morris Plains, N.J.(U.S.A.)

1 A. L. Babson, P. O. Shapiro, 13. A. R. Williams and G. E. Phillips, Clin. Chim. Acta, 7 (1962) 199 .

Received October 2oth, I962

Chin. Chim. Acla, $8(1963) 326-327$

\title{
A laboratory-table for ultra-micro techniques
}

Ultra-micro techniques for routine clinical analysis are nowadays in use in many laboratories and their still spreading application shows that they are very valuable. These techniques ask for a quiet laboratory.

With this in mind we have developed a special working-bench or table, which incorporates all the necessary apparatus at the appropriate place, at the same time leaving a clean working space, which is effected by placing the apparatus under instead of on the table.

Fig. I gives an overall view of our "unit" and in Fig. 2 the location of the different apparatus can be seen. At the left is a stainless-steel waterbath for 48 tubes, placed in a removable rack. The water is pumped round by a pump which is situated at the backside of the table. Temperature control is in the left box. In the middle-front is the colorimeter cuvet with filterholder and dark-current shutter. The cuvet is of the stationary type and is emptied by a small, noiseless suctionpump which again is 


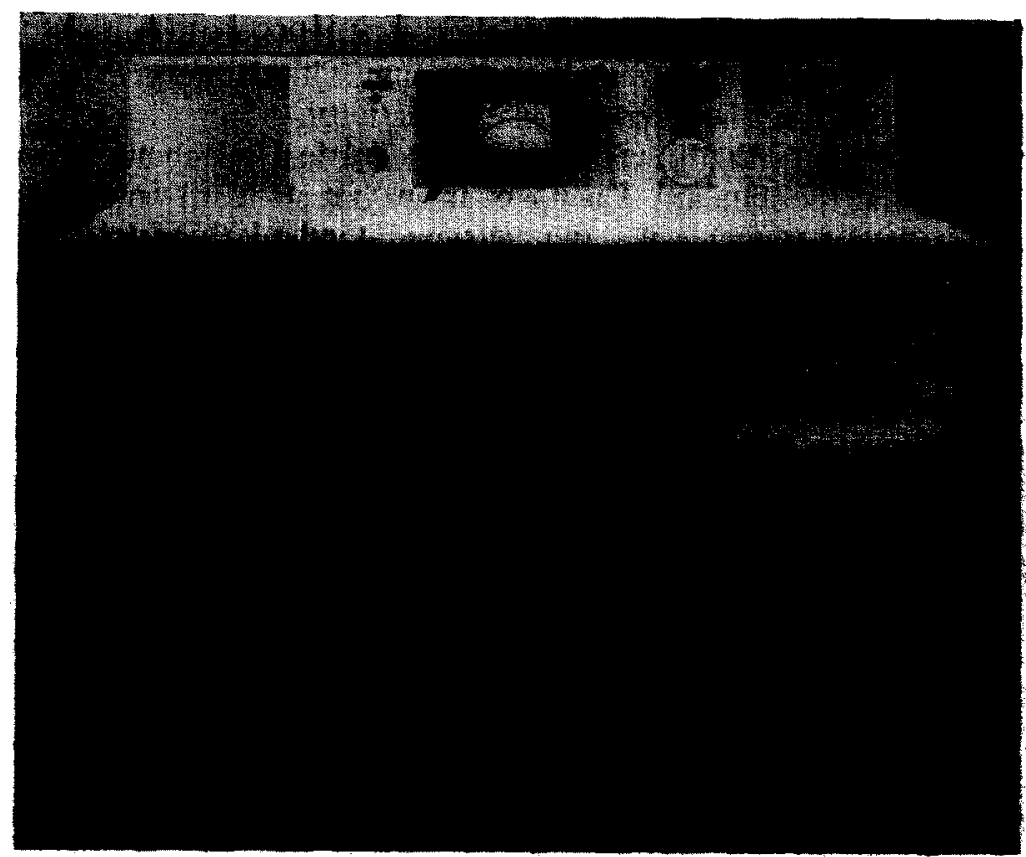

Fig. I.

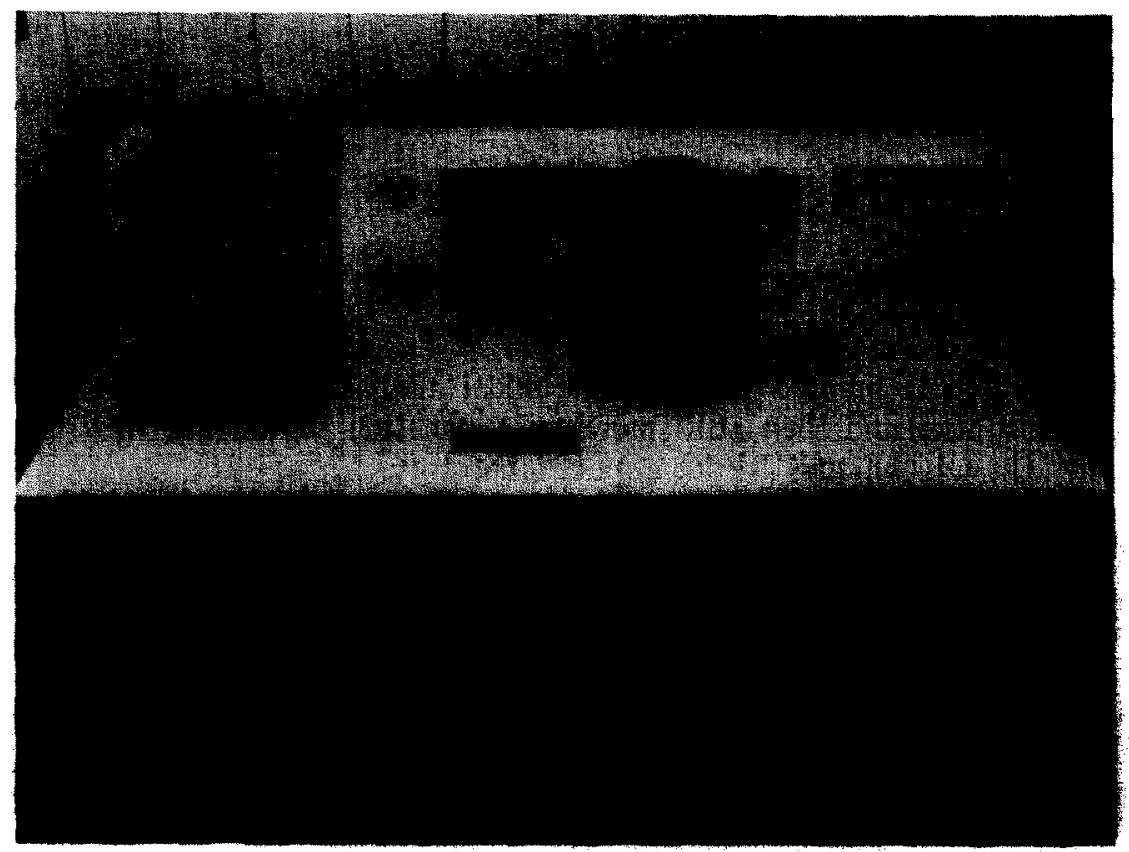

Fig. 2. 
situated in the left box, together with the receiving flask. The other parts of the colorimeter are placed behind the panel. At the right side before this panel is the centrifuge which has its controls for time and speed on the panel. Mixing is done on a small rotating cylinder which protrudes at an angle through the table. It is actuated by a knee-switch. The righthand side of the table remains free and gives ample space for pipets, notebook etc.

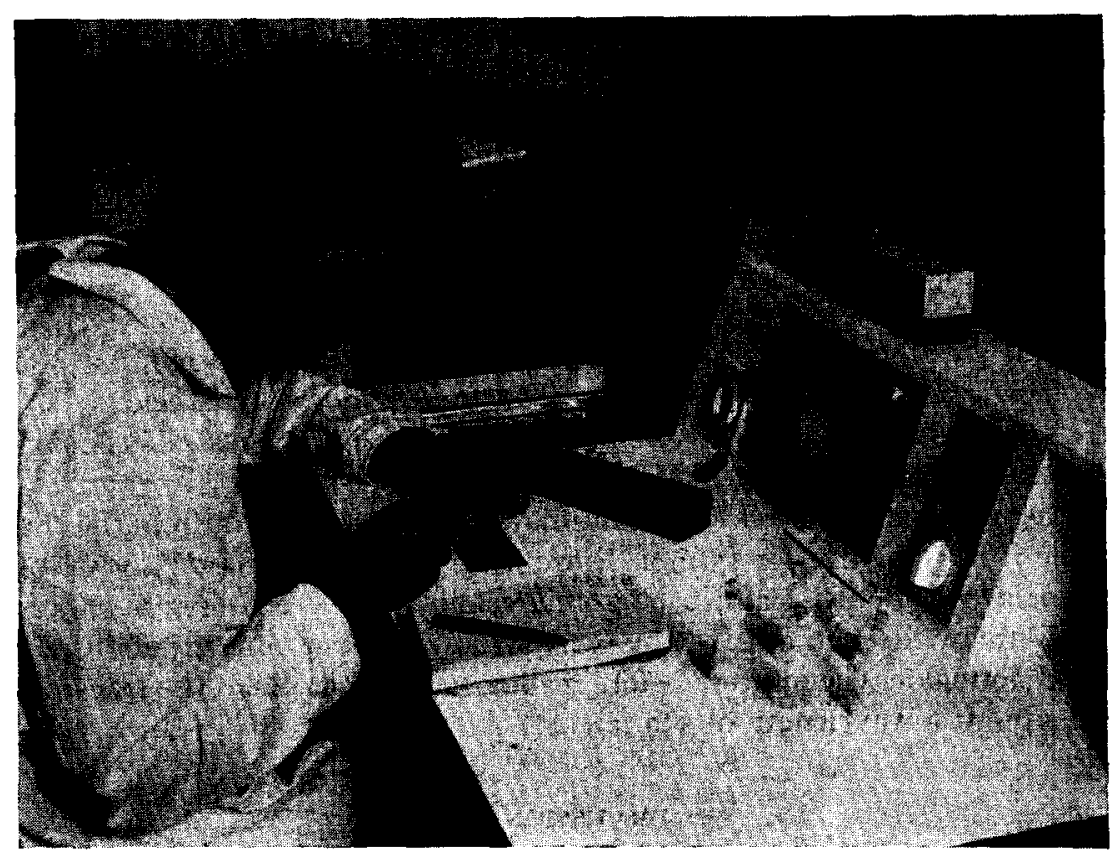

Fig. 3 .

Fig. 3 shows that under working circumstances the table provides comfort and a clear, unobstructed view on all the necessary parts.

Apart of the advantage of adaptation to special working conditions is the possibility of placing one or more tables at every suitable place, thus facilitating to a great extent the introduction of ultra-micro techniques.

Laboratory for Clinical Micro-chemistry, P. Reinouts van Haga State University, Utrecht (The Netherlands)

Received October 29th, I962 